\title{
FDM MODELED POLYMER TOOLING FOR PLASTIC INJECTION MOLDING
}

\author{
Sagar Kumar and Amit Kumar Singh \\ Department of Mechanical Engineering \\ Malaviya National Institute of Technology, Jaipur
}

\begin{abstract}
Rapid Prototyping is being accepted globally by industries for its potential in saving on process time and cost. Rapid Tooling helps Rapid Prototyping grow beyond its conventional Feel \& Fit status to Feel Fit Function status and is increasingly becoming popular. However, potential of rapid prototyping for normal production run is still not being realized. In that situation Rapid Tooling becomes a viable alternative. The greatest opportunity for rapid tooling implementation is the use of Additive Manufacturing (AM) technology. Further, polymer based direct rapid tooling provide large cost reduction and can also be readily accessible by industries. With the advances in materials along with the new access and low cost plastic based-AM equipment, direct use Polymer Rapid Tools (PRTs) would be a far more advantageous option in creating injection molds for low and highly flexible production. However, the use of polymer based direct rapid tooling by industries is curtailed due to the issues with the dimensional stability of the polymer based rapid tooling molds. Apart from dimensional tolerances, there are also issues with the life of these polymer based mold as they wear fast and are also not able to sustain high injection pressures in an Injection molding machine. Another, major problem with the polymer based rapid tooling is the poor thermal conductivity of polymeric materials due to which there is an increase in the cooling time and ultimately leading to decrease in productivity. Therefore, before proposing polymer based rapid tooling as a solution to industries to cut down the product development time and bring down the costs, a thorough study of the issues related to the same is imperative. This paper investigates the dimensional accuracy of striker component produced by ABS mold inserts. For dimensional accuracy a reverse engineering technique $3 D$ scanning is used which is compared with CAD file and inspected with COMET plus software. Further, the outputs are validated with vernier caliper. The mold insert is manufactured by Fused Deposition Modeling (FDM) technology which is used on injection molding machine
\end{abstract}

\section{KEYWORDS}

Fused deposition molding, Hand Injection molding, Rapid tooling and Reverse engineering

\section{INTRODUCTION}

With short production cycles, excellent surfaces of the products, tight tolerance complete automation capability and facile molding of complex part geometry,Injection molding(IM) is crowned as the most popular molding process for manufacturing thermoplastic parts. However IM requires complex and costly tooling and it is almost uneconomical to plan a short production 
International Journal of Advances in Materials Science and Engineering (IJAMSE) Vol.7, No.1, January 2018

run. Hence IM personals are confronted when a one-off production or trial run for product development are warranted[1].

The proliferation of rapid Prototyping (RP) tends to rope in IM tool design and development simplified. RP in late eighties began with rapid generation of prototypes for feel and fit purposes. Today, Rapid prototyping(RP) has emerged as a third industrial revolution reengineering the entire manufacturing transforming the way in which products and systems are designed and manufactured asa fascinating area of study called rapid manufacturing (RM)covering $>50 \%$ of the additive manufacturing (AM) output figure1. This is affected through emergence of a new field of science called Rapid Tooling (RT).RT is being expanded asSoft Tooling, Hard Tooling, Direct Tooling, and Indirect Tooling and is the link between RP and RM.

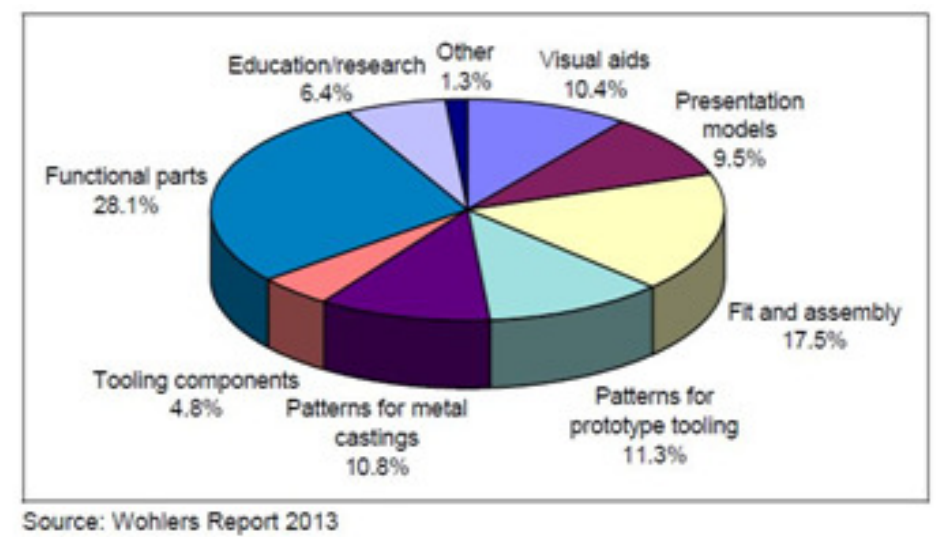

Figure1. Applications of additive manufacturing[2]

Today, RP technology is slowly being recognized as a class of commercially viable production techniquescharacterized by significantly low tooling cost and lead time[2]. The revenues from the production of parts for final products represents $34.7 \%$ of the entire market for additive manufacturing (AM) to reach the $\$ 1$ billion mark.Wohler's represented in figure 2 .

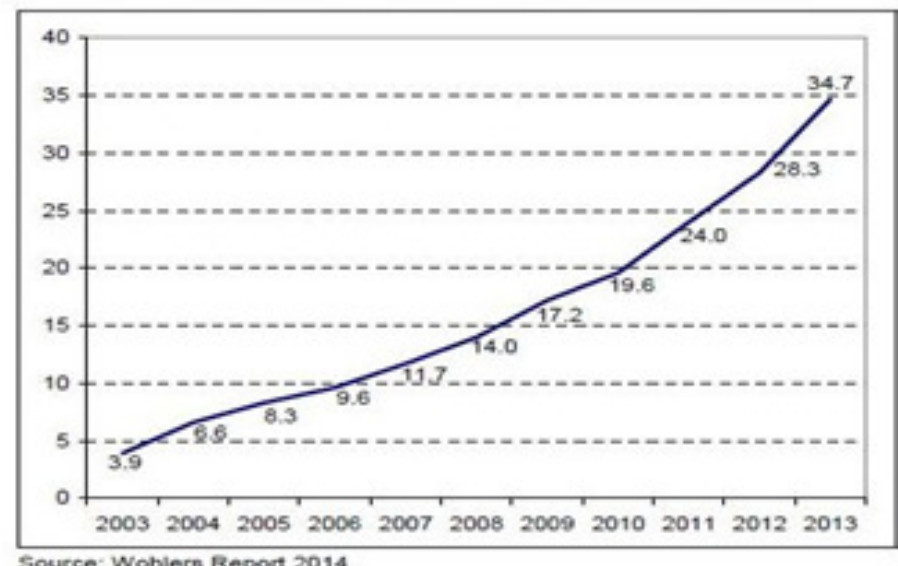

Figure2.Revenues from the production of parts for final products[3] 
International Journal of Advances in Materials Science and Engineering (IJAMSE) Vol.7, No.1, January 2018

$\mathrm{AM}$ has a host of technologies(FDM/SLA/SLS/3D printing/poly jet) employing different types of feed materials like solids(filaments), liquids( resins),powders but majority employ polymer based feed stock hence the thermal resistance and fatigue strength are always a concern when it was employed to endure extreme conditions of stress and temperature entailed in tooling. However as per the sporadic information available in the literature; the development of SLA based IMtooling were seen attempted[4-7]however no commercialization has yet been reported.Metal based AMs are the best but are unaffordable. FDM with its conventional ABS and poor part density it is being ruled out for IM tooling project. One promising option is FDM based Polyjettechnologywhich employs digital ABS,rubber like elastopolymers etc. This paper investigates the development of IM tooling through Polyjettechnology

\section{METHODOLOGY}

Polyjet technology is a variant of FDM technology licensed to Stratasys. Stratasys Objet series of RP machines employ this methodology [8]. These machines manifest extreme level of surface finish ( $\mathrm{Ra} 3$ ) and partdefinition with improved density, physical properties etc.

Before manufacturing of mold inserts of part component on 3D Polyjet it is created on 3D modeling software Creo-3.0 according to theirdimension as shown in Figure 3.

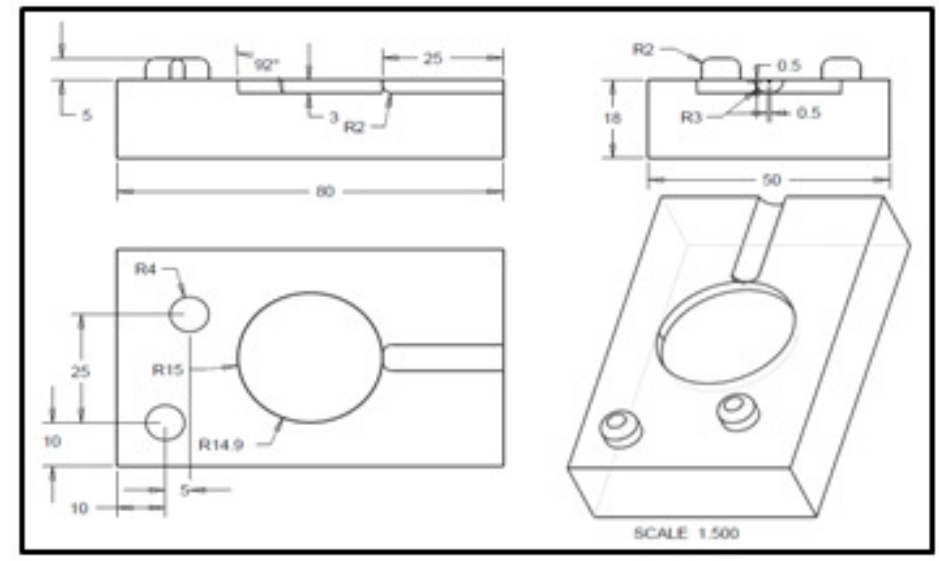

Figure3.Designed geometry with dimension of striker mold

\subsection{POLY JET WORKING PRINCIPLE}

Poly-Jet Modeling is an additive manufacturing technique with a selectively ink jetting of UVcurable photopolymer resin as shown in Figure4. First, the photopolymer is jetted onto the buildupplatform by the printing head. Simultaneously the photopolymer drops are leveled by a roller and solidified by a UV-light. Subsequently the platform is lowered. Like this, a part is generated layer by layer 
International Journal of Advances in Materials Science and Engineering (IJAMSE) Vol.7, No.1, January 2018
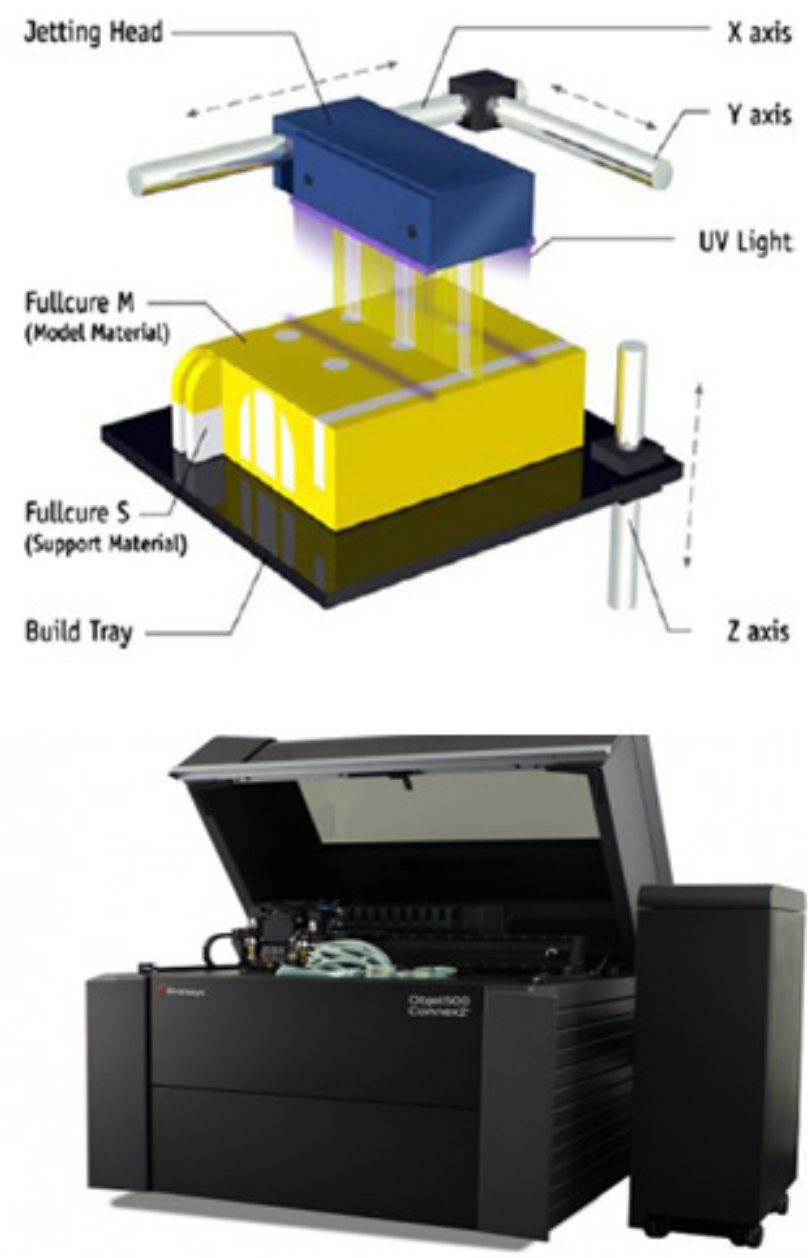

Figure4. Polyjet 3D printer for printing core and cavity of Digital ABS mold [8]

Table1. Parameters of Ployjet 3D printer Component/mold

\begin{tabular}{|l|l|}
\hline Type & Stratasys Object 350 connex \\
\hline Matterial & Digital ABS \\
\hline Bed Temperature & $35^{\circ} \mathrm{C}$ \\
\hline Chamber Temperature & $35^{\circ} \mathrm{C}$ \\
\hline Layer Thickness & $0.032 \mathrm{~mm}$ \\
\hline
\end{tabular}

Digital ABS is suitable for simulating parts that require high impact resistance and shock absorption with its impact resistance of $65-80 \mathrm{~J} / \mathrm{m}$ and a heat deflection temperature of $58-68^{\circ} \mathrm{C}$ $\left(136-154^{\circ} \mathrm{F}\right)$. It is high temperature material synthesizes heat resistance with unprecedented dimensional stability. 

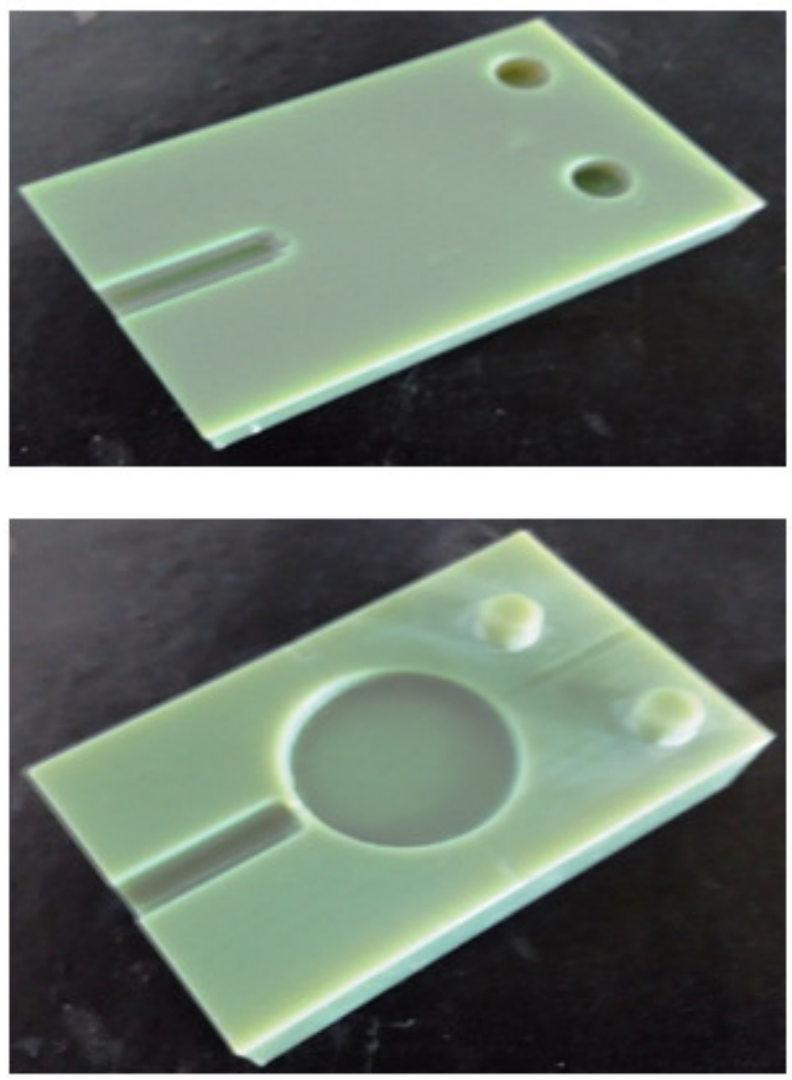

Figure 5. 3D printed core and cavity of striker

The material can simulate the thermal performance of engineering plastics and is ideal for testing applications such as hot polymer flow in mold insert cavity.

\section{HAND INJECTION MOULDING MACHINE}

Thermoplastic or thermoset is heated to plastic ate in cylinder at controlled temperaturethen forced under pressure through a nozzle into sprue, runner, gates and cavities of mould. The resin undergoes solidification rapidly.Aftersolidification of molten material mould is opened and the part gets eject. Injection moulding is growing in the making of glass-reinforced parts. The mold forms, shapes and cools the plastic material into the required product shape[9-10]. The temperature setting for the PP injection is based on the MP of the PP $\left(164^{\circ} \mathrm{C}\right)$ it was advisable to set a temperature $180^{\circ} \mathrm{C}$ to start with the experiment. The PP beads were heated in the barrel to test the melting and oozing out of the liquid plastic threads the nozzle by manually pressuring through the plunger. The molding was uniformed hence the temperature was gradually increased in steps from 190, 200 and $210^{\circ} \mathrm{C}$. 
International Journal of Advances in Materials Science and Engineering (IJAMSE) Vol.7, No.1, January 2018

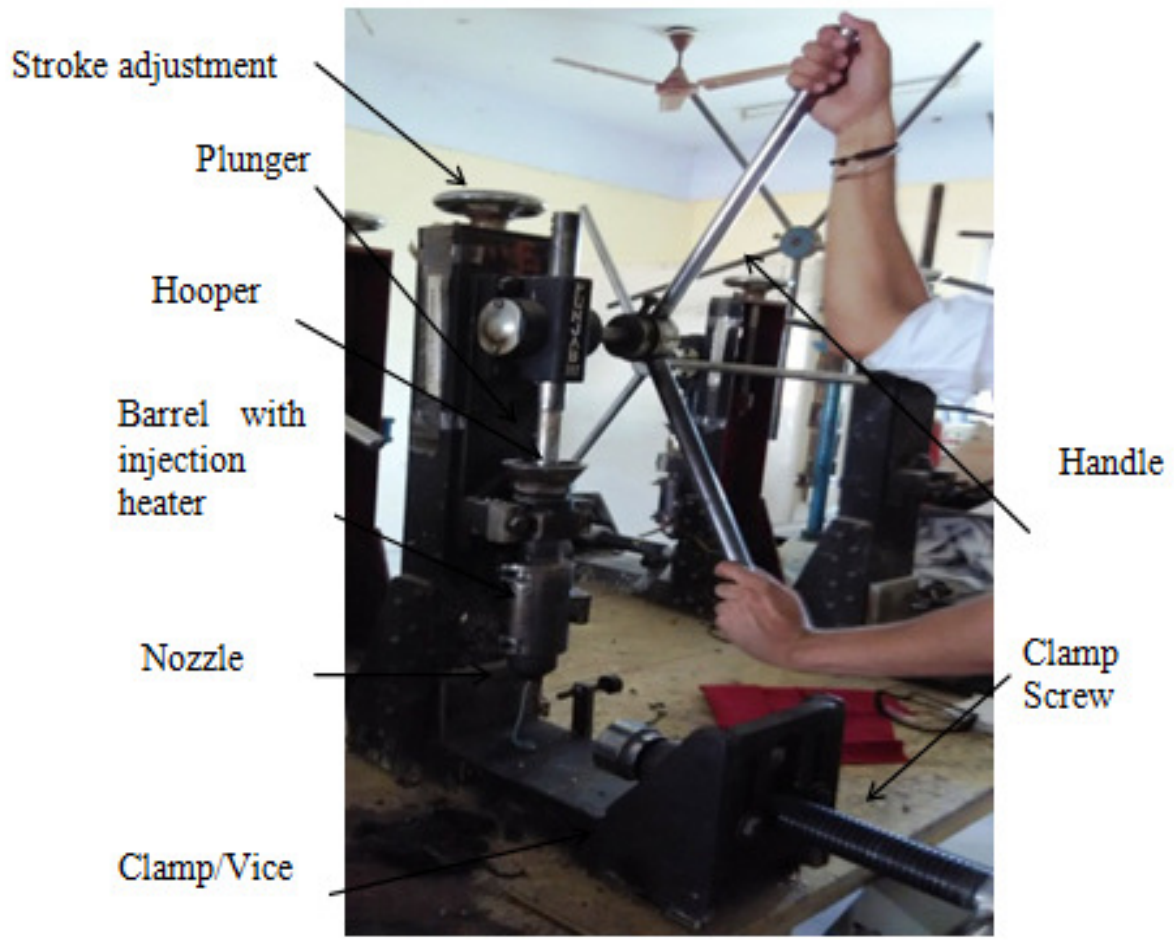

Figure6.Hand Injection Molding (HIM) Machine Set with mold for trial runs

It was observed that the mold was getting damaged at the injection point due to applied pressure (at the plunger runner contact area).

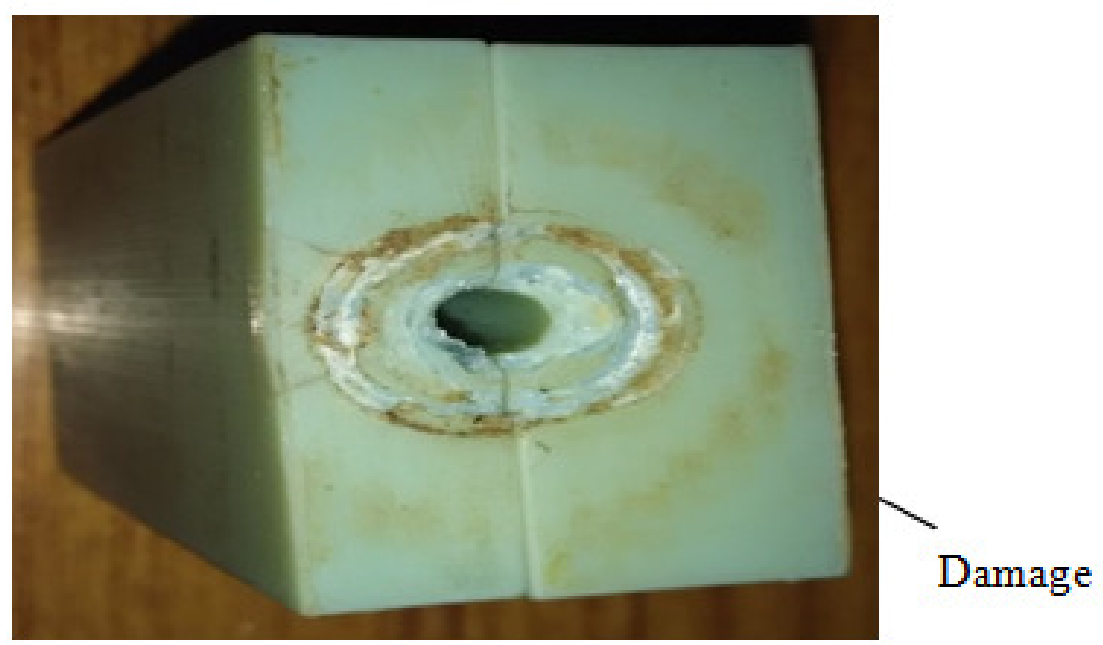

Figure7. Damaged mold at the injection point 
International Journal of Advances in Materials Science and Engineering (IJAMSE) Vol.7, No.1, January 2018

Always it needs to avoid the direct machine nozzle contact to printed tool.Here a metals (MS) plate is used to solve the problem by minimizing temperature and pressure intensity at the injection point and converted point load to uniformly distributed load.

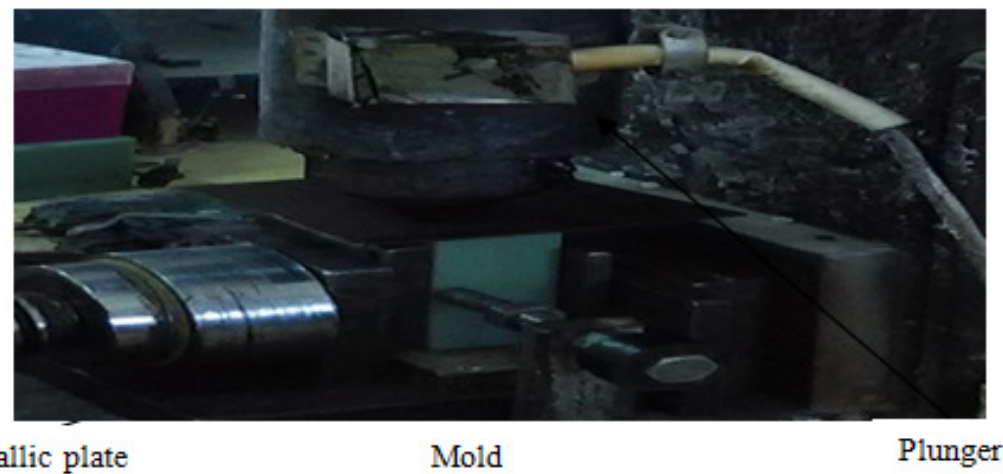

Figure8. Metals (MS) plate is used to solve the problem by minimizing temperature and pressure intensity at the injection point

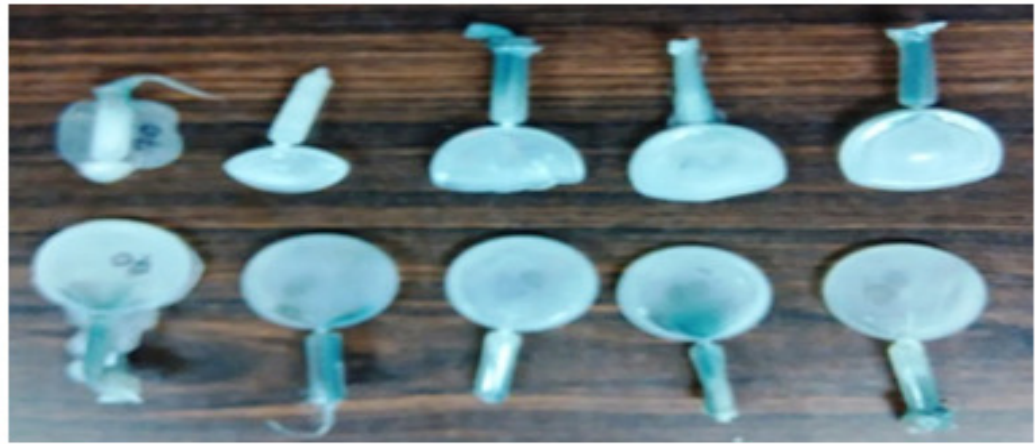

Figure9.Progressive stages of the component made in the trial runs

During the run time whenever the mold got over heated the component got sticky and gummy and did not form well. It needs to be probed. Designing of proper Cooling channels may be a solution. 




Figure 10.Quality part (sticker) production in the HIM process

The next figure shows the damage and non- formation of the part due to high temperature $200^{\circ} \mathrm{C}$ and above. The part non-formation during the run was not possible to run the mold continuously.It was found the temperature $190^{\circ} \mathrm{Cwas}$ good to get excellent mouldings.The product coming from the nozzle temperature controlling from 170 to $190{ }^{\circ} \mathrm{C}$ is acceptable.

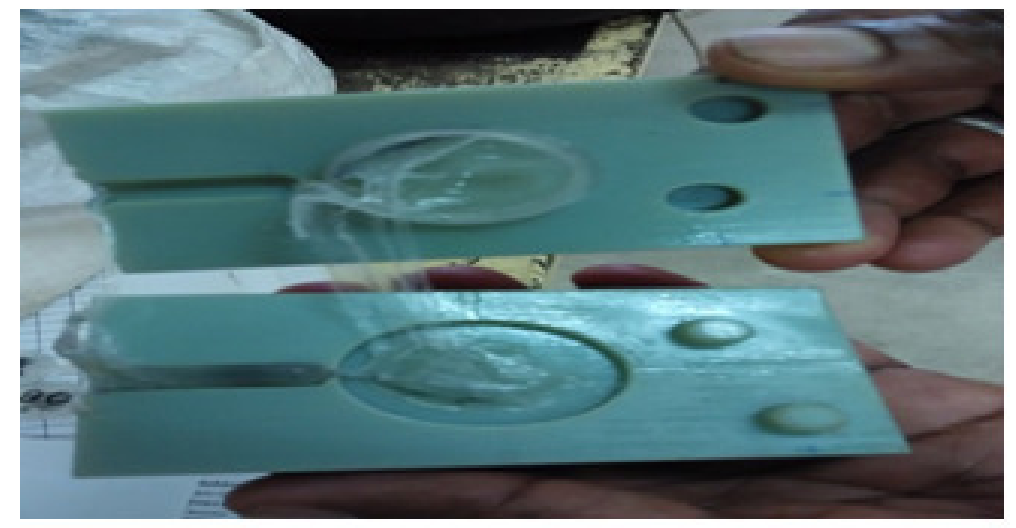

Figure11. Part sticks to the mold cavity

It was found at temperature above $200^{\circ} \mathrm{C}$ the part formed were rejected. This was applicable even at low temperature injection after a brief run of 5 shots. This was due to mold getting over heated due to dull dissipation of heat from the mould cavity

\section{3D SCANNER}

It is a device that captures the features of the physical object using lasers, lights or x-rays and generates dense point clouds or polygon meshes.Before scanning a striker mold part is placed on the table. The physical object can be digitized using contact 3D scanning technologies like 
International Journal of Advances in Materials Science and Engineering (IJAMSE) Vol.7, No.1, January 2018

Coordinate Measuring Machine (CMM) or noncontact 3D scanning technologies like laser scanners, structured light digitizers, etc. [11].

The point cloud of a manufactured part will be aligned to a CADmodel and compared to check for differences after inspection [12, 13].

The part quality- The part production procedure was established in the HIM machine and the reading on dimensional accuracy of the part are shown in figure 12 .
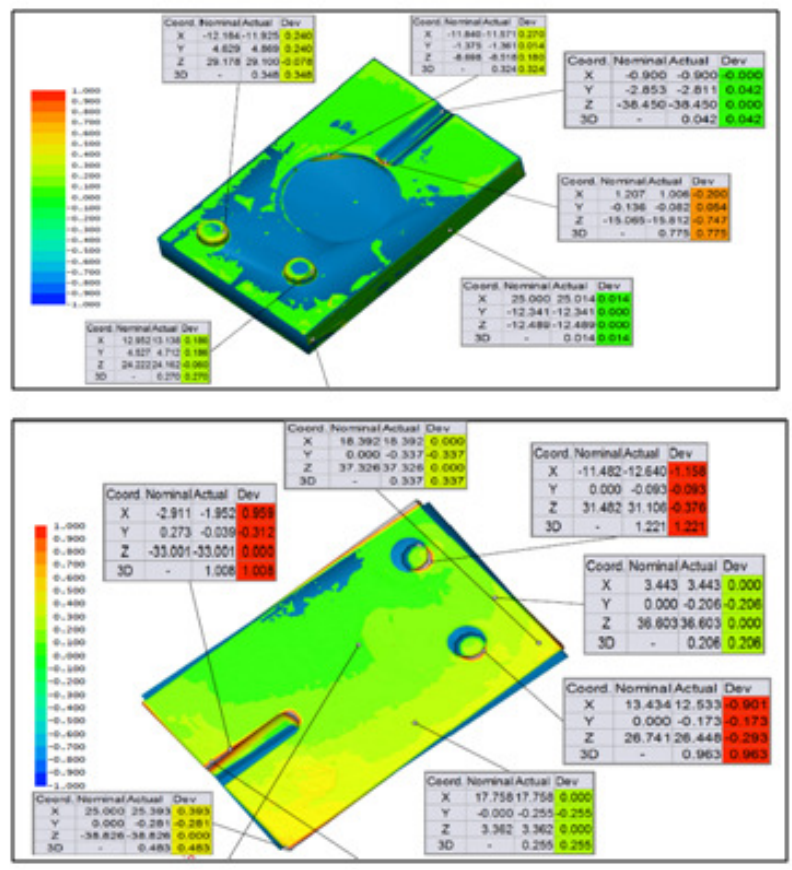

Figure12. Inspection result using 3D scanner integrated with COMET plus and Inspect Plus. 




Figure13. 3D scanner for inspection of part component

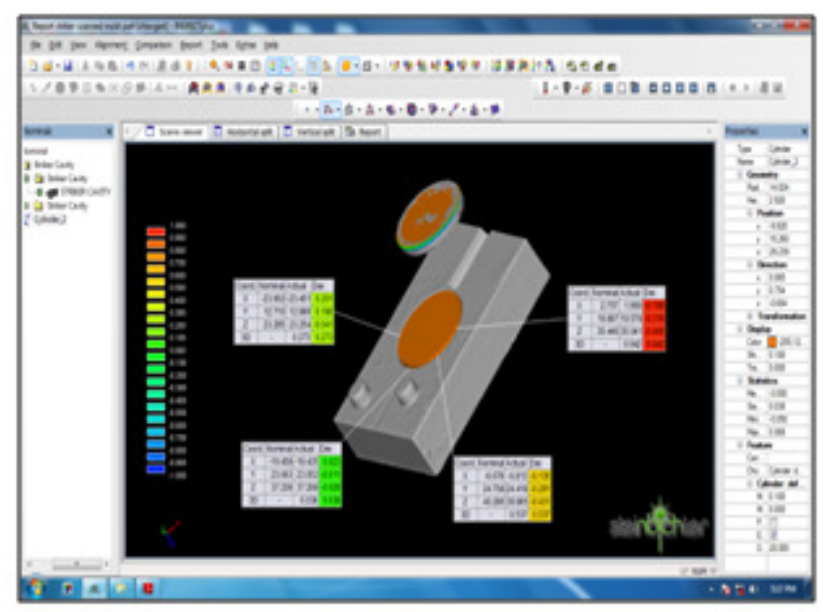

Figure14. Inspection results of component

Table2. Dimension of measured part using 3D scanner

\begin{tabular}{|l|l|l|l|}
\hline Dimensions & Nominal & Mold & Part \\
\hline Diameter & 30 & 29.628 & 29.54 \\
\hline Thickness & 3 & 2.920 & 2.98 \\
\hline
\end{tabular}

The Digital Caliper is a precision instrument that can be used to measure internal and external distances extremely accurately. The example shown below is a digital caliper as the distances / measurements, are read from a LCD display. The display is turned on with the on/off button. The external jaws should then be brought together until they touch and the zero buttons should be pressed. The digital caliper can then be used to measure distances. Always go through this procedure when turning on the display for the first time. 


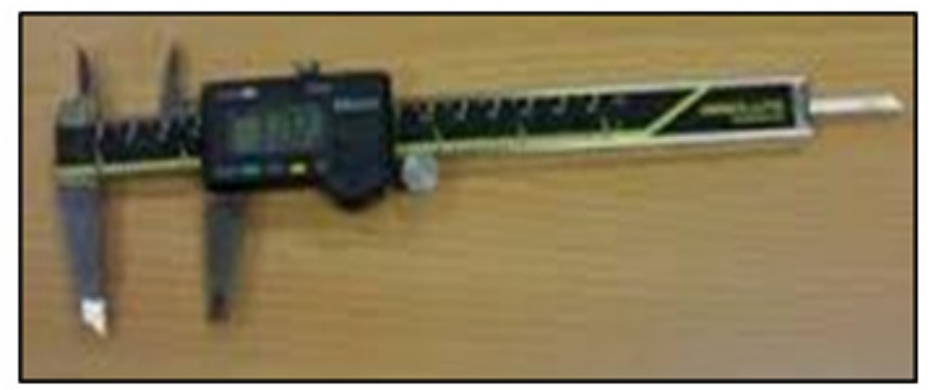

Figure15. Digital Vernier caliper

The material to be measured is placed between the external jaws and they are carefully brought together. The locking screw is tightened so that the jaws do not move apart. The digital display can then be read. The distance can be read by in metric and imperial by pressing the inch/mm button.

Table3.Dimensional results using Vernier caliper

\begin{tabular}{|l|l|l|}
\hline SI no & Thickness & Diameter \\
\hline 1 & 2.9 & 29.31 \\
\hline 2 & 2.98 & 29.54 \\
\hline 3 & 2.95 & 29.36 \\
\hline 4 & 2.95 & 29.41 \\
\hline 5 & 2.93 & 29.29 \\
\hline 6 & 2.89 & 28.9 \\
\hline 7 & 2.89 & 29.32 \\
\hline 8 & 2.96 & 29.15 \\
\hline 9 & 3.02 & 29.26 \\
\hline 10 & 2.96 & 29.20 \\
\hline Average & 2.943 & 29.274 \\
\hline
\end{tabular}

\section{Conclusion}

The injection molding is an intensive mass production process hardly amenable to product developmental short run trials. In the fast changing product style and customer taste the plastic industries are felt the paradox of prototyping and mass production increasingly. Hence it's a global need to introduce new Time Compression Technologies (CTC) to manufacturer prototyping molds economically.

Polyjet based additive manufacturing (AM) is potential and promising CTC technology to prototype injection molds for typical short runs. 
International Journal of Advances in Materials Science and Engineering (IJAMSE) Vol.7, No.1, January 2018

Polyjet CTC is going to be a viable answer to the long standing prototyping issues in the polymer injection molding industries. As compared with measure dimension through vernier caliper the scanned part of striker cavity is almost similar.

\section{REFERENCE}

[1.] LouayElsoufi, Khaled Khalil, Willy Charon, Remy Lachat (2015)Influence of the Thermoplastic type on the Thermal Evolution of a Piezoceramic Patch during the Manufacture of a Smart Thermoplastic Part by Injection Molding Process.

[2.] Wohlers Report 2014 - 3D Printing and Additive Manufacturing State of the Industry, Annual 665 Worldwide Progress Report, Wohlers Associates, 2014.

[3.] Wohlersassociates.com, Production of Parts for Final Products is Now 34.7\% of the Market for Additive Manufacturing

[4.] Jose Carvalho Ferreira, Eduardo Santos, Hugo Madureira and Joao Castro (2015) Portugal, Integration of $\mathrm{VP} / \mathrm{RP} / \mathrm{RT} / \mathrm{RE} / \mathrm{RM}$ for rapid product and process development.

[5.] KhurramAltaf, Ahmad Majdi Abdul Rani and Vijay R. Raghavan (2015)Malaysia Prototype production and experimental analysis for circular and profiled conformal cooling channels in aluminium filled epoxy injection mould tools

[6.] B. Vaupotic, M. Brezocnik, J. Balic (2006) Use of PolyJet technology in manufacture of new product.

[7.] J. Kechagias, P. Stavropoulos, A. Koutsomichalis, I. Ntintakis and N. Vaxevanidis Dimensional Accuracy Optimization of Prototypes produced by PolyJet Direct 3D Printing Technology

[8.] www.stratasys.com

[9.] SeyedFaridSeyedShirazi, Samira Gharehkhani, Mehdi Mehrali,HoomanYarmand, Hendrik Simon CornelisMetselaar, NahrizulAdibKadri and Noor Azuan Abu Osman (2015) Malaysia, A review on powder-based additive manufacturing for tissue engineering: selective laser sintering and inkjet 3D printing

[10.] C. E. Folgar, L. N. Folgar, and D. Cormier Multifunctional material direct printing for laser sintering systems.

[11.] Carmen GabrielaBacila, Zoltan-Gabor BAKI-HARI (Romania)The rapid tooling in the product development

[12.] Sivadasan M, N K Singh, A K Sood,"Use of FDM in Investment Casting and risk of using SLS process" Intl.J.of Applied Research in Mechanical Engg ( IJARME) ISSN No. 2231 -5950, Vol2 Issue-1(2012) pp 1-5.

[13.] Liu, G.H., Y.S. Wong, Y.F. Zhang and H.T. Loh, 2003. Error based segmentation of cloud data for direct rapid prototyping. 